\title{
Development and Characterization of PLA Composites with High Contents of a Brazilian Refractory Clay and Improved Fire Performance
}

\author{
Letícia Heldt Rabelo ${ }^{a}$, Rodrigo Amorim Munhoz ${ }^{a}$, Juliano Marini ${ }^{b *}$ (D), Sylma Carvalho Maestrelli ${ }^{a}$ (D) \\ ${ }^{a}$ Universidade Federal de Alfenas, Instituto de Ciência e Tecnologia, Rodovia José Aurélio Vilela, \\ 11999, 37715-400, Poços de Caldas, MG, Brasil. \\ ${ }^{b}$ Universidade Federal de São Carlos, Departamento de Engenharia de Materiais, Rod. Washington \\ Luís, km 235, 13565-905, São Carlos, SP, Brasil.
}

Received: September 3, 2021; Accepted: October 25, 2021

\begin{abstract}
Aiming to overcome poly(lactic acid) (PLA) limitations regarding flammability and high costs, a highly refractory clay (RC) was employed to produce PLA/RC composites. The composites with clay contents of $0,2.5,10$ and $15 \mathrm{wt} \%$ were produced by extrusion, conformed by injection molding, and characterized by thermogravimetric analysis (TGA), differential scanning calorimetry (DSC), mechanical analysis, scanning electron microscopy (SEM), Fourier Transform Infrared Spectroscopy (FTIR), statistical analysis of variance (ANOVA) and flammability tests. The overall thermal stability of the materials was not affected by the incorporation of clay to the polymer matrix; improvements around 25\% for Young's modulus and slight increase in flexural and impact strength, when compared to neat PLA, were obtained; ANOVA showed the possibility of incorporating higher loads of clay, $10-15 \mathrm{wt} \%$, in order to make the final material more cost effective. PLA/RC composites demonstrated self-extinguish behavior for the flame even at a lower clay content.
\end{abstract}

Keywords: PLA, refractory clay, mechanical properties, thermal properties, flammability.

\section{Introduction}

The global demand for development of biopolymers continuously increased in recent decades, mainly due to social awareness and environmental concerns regarding the large consumption of petroleum-based polymers, their final destination and the limitation of fossil resources ${ }^{1,2}$. Industry and academy have made great efforts to develop and study bio-based polymers originated from renewable sources and susceptible to biodegradation ${ }^{2}$.

Poly(lactic acid) (PLA) is an aliphatic polyester, derived from renewable sources, such as sugarcane, beet-root, corn, etc., and is produced through polymerization of lactic acid or by the ring opening of its cyclic dimer (lactide) $)^{3-6}$. It has emerged as a promising biopolymer among those developed over the last few decades, and has become one of the leading materials on the market with regard to the replacement of petroleum-based polymers ${ }^{7,8}$ due to its set of characteristics (e.g. high modulus and strength, biocompatibility, low toxicity, biodegradability, easy processability $)^{4,6,9,10}$, which allow its use in the most diverse fields. PLA still has some flaws with respect to flammability, thermal stability, toughness, impact strength and high costs compared to petroleum-based polymers, which hinders its ability to replace commodities polymers $^{6,9-12}$.

Polymers in general, including PLA, are highly combustible materials due to its organic chemical structure; with the growing use of polymers in everyday life, it has become essential to tackle polymers flammability limitations to

*e-mail:juliano.marini@ufscar.br broaden their use in the most diverse fields. The inhibition and suppression of the polymer combustion process can be achieved by the incorporation of a flame retardant (FR) to the polymer matrix, acting physically or chemically. The chemical action happens for FR added to the polymer matrix during its synthesis; during combustion, the FR promotes chemical modification of the combustion process either in the condensed or in the gas phase. The physical action can occur in three different ways: i) when the FR promotes the dilution of flammable volatiles due to the formation of inert gases; ii) cooling of the reaction medium promoted by the endothermic decomposition of the FR; iii) the formation of a protective layer on the surface of the polymer material, helping to suppress the transfer of combustible gases between the gas phase and the polymer ${ }^{13-15}$.

Regarding fire resistance limitations, a great number of researches have studied the incorporation of different FR to PLA matrix. Among the most studied materials are halogenfree flame retardants (e.g. phosphorous FR), intumescent FR and different fillers that can also act as flame retardants to polymers, such as carbon nanotubes, layered silicates, metal oxides, expanded graphite; they act mostly in the condensed phase forming a protective layer on the polymer surface ${ }^{2,16,17}$.

Clay minerals are part of every-day life since early times, being of great abundance worldwide and of low $\operatorname{cost}^{18,19}$. They are hydrous aluminum silicates structured in stacked octahedral and tetrahedral sheets, forming very fine sized particles; it is the layered structure and composition that differentiate the various classes of clays from each other, e.g. smectites, kaolinite, illite, vermiculite, and sepiolite ${ }^{18-22}$. Many researches 
have been carried out using layered silicates to produce PLA/ clay composites with enhanced mechanical, thermal and fire properties; from those studies, it was noticed that montmorillonite (MMT), halloysite nanotubes (HNT) and sepiolite (SEP) are the most commonly used types of clay ${ }^{9,10,23-28}$. Of common occurrence, kaolinite should also be given attention; it is a clay mineral with chemical composition $\mathrm{Al}_{2} \mathrm{O}_{3} \cdot 2 \mathrm{SiO}_{2} \cdot 2 \mathrm{H}_{2} \mathrm{O}$ and $\mathrm{a}$ 1:1 structure, i.e. one octahedral layer bonded to one tetrahedral sheet by hydrogen bonds ${ }^{18,21,29}$. Refractory clays (RC) are part of the kaolinite group, withstand high temperatures (at least $1300^{\circ} \mathrm{C}$ ) without suffering deformation or melting; in addition, they have a high alumina content, and its refractoriness is determined by the silica/alumina ratio ${ }^{21}$.

In Brazil, deposits of RC are spread over the states of Minas Gerais, São Paulo and Santa Catarina; in Poços de Caldas region (Minas Gerais), it is found a highly refractory non-plastic clay, with high alumina content (about 52\%), surface area of $37.32 \mathrm{~m}^{2} / \mathrm{g}$, but without a proper use due to its lack of moldability ${ }^{30}$. Thus, the aim of this research is to produce PLA/refractory clay biocomposites to face the PLA limitations in terms of flammability and also to make the final material cheaper than neat PLA, without degrading the mechanical and thermal properties of the polymeric matrix; for this purpose, clay contents higher than those commonly seen in literature (up to $5 \mathrm{wt} \%$ ) should be used; also, it is believed that the highly refractory clay can have an interesting effect on the composite flame retardance; it is worth mentioning that no surface treatment was employed in order to understand the real role of the clay refractoriness on flammability, thermal and mechanical results and to prevent any costs increase.

\section{Experimental}

\subsection{Materials}

The polymer matrix used was PLA(Ingeo ${ }^{\mathrm{TM}}$ Biopolymer 7001D) from NatureWorks LLC, USA, with specific density of $1.24 \mathrm{~g} / \mathrm{cm}^{3}$, melt flow index (MFI) of $6.0 \mathrm{~g} / 10 \mathrm{~min}$ $\left(210^{\circ} \mathrm{C} / 2.16 \mathrm{~kg}\right), \mathrm{M}_{\mathrm{w}}$ of $83,300 \mathrm{~g} / \mathrm{mol}$ and $1.5 \%$ of D-isomer ${ }^{30}$.

Highly refractory clay (RC) was kindly provided by Togni S/A Materiais Refratários. The clay was extracted by the company from a deposit in the region of Poços de Caldas/ Brazil, and it was supplied in the powder form, which was previously studied by Maestrelli and coworkers ${ }^{31}$. The chemical analysis for this clay demonstrated that it is mainly made up by $\mathrm{Al}_{2} \mathrm{O}_{3}(52 \%)$ and $\mathrm{SiO}_{2}(15 \%)$ and has a small alkalis content, this combination (high alumina and low alkalis content) renders it a highly refractory behavior. Also, this material has a low plasticity index (5.6), shows a superficial area of $37.32 \mathrm{~m}^{2} / \mathrm{g}$ and particle size distribution in which $93 \%$ of the particles are smaller than $44 \mu \mathrm{m}$ (mean particle size of $10 \mu \mathrm{m})^{31}$.

\subsection{Methods}

\subsubsection{Preparation of PLA/Clay composites}

The composites were prepared by melt mixing with RC contents of $0,2.5,10$ and $15 \mathrm{wt} \%$ (named PLA, PLA/2.5RC, PLA/10RC and PLA/15RC, respectively). Prior to processing, PLA granules were powdered in a Mikro-Bantam cryogenic mill (Micron Powder Systems) to achieve a similar particle size as for the refractory clay, helping on the posterior feeding of the mixture. PLA powder and RC were dried at $60{ }^{\circ} \mathrm{C}$ for about $18 \mathrm{~h}$ in a TECNAL TE 394/2 conditioning oven, then both polymer and clay were mechanically mixed at the proper ratios prior to being fed in the extruder.

Neat PLA (reference material) and PLA/RC composites were produced under the same conditions in a MP19 co-rotating twin-screw extruder (B\&P Process Equipment Systems, L/D 25:1) with a temperature profile of $170 / 175 / 185 / 190 / 190{ }^{\circ} \mathrm{C}$ from hopper to extrusion die and screw speed of $100 \mathrm{rpm}$. After extrusion, the materials were pelletized and dried at $60{ }^{\circ} \mathrm{C}$.

Injection molding of the composites and the reference material were performed in an Arburg 270V injection molding machine with screw diameter of $25 \mathrm{~mm}$ (temperature profile of $175 / 178 / 180 / 180 / 185{ }^{\circ} \mathrm{C}$, injection flow rate of $20 \mathrm{~cm}^{3} / \mathrm{s}$ and injection pressure adjusted between 940 and 1050 bar, according to the sample) coupled to a cooling and heating unit HBW140 (HB THERM) in the mold (mold temperature of $30^{\circ} \mathrm{C}$, cooling time of $45 \mathrm{~s}$ ). Standardized specimens, according to ASTM D638-14 ${ }^{32}$ and ASTM D790-1733, were obtained.

\subsubsection{Flame retardancy behavior}

The Underwriters Laboratories 94 (UL-94) horizontal and vertical burning tests were performed, according to ASTM D635-18 $8^{34}$ and ASTM D3801-19 ${ }^{35}$ respectively, on $126 \mathrm{~mm}$ x $13 \mathrm{~mm}$ x $3 \mathrm{~mm}$ specimens. Five specimens for each composition were submitted to the vertical burning test (UL-94V) that evaluates the self-extinguish behavior of the flame and dripping of the material.

For the horizontal burning test (UL-94HB), three specimens for each composition were tested to evaluate the linear burning rate of the samples, which could be calculated using Equation 1:

$$
V=\frac{60 L}{t}
$$

where $\mathrm{V}$ is the linear burning rate in $\mathrm{mm} / \mathrm{min}, \mathrm{L}$ is the damaged length ( $\mathrm{mm}$ ) and $\mathrm{t}$ is the time (s) elapsed during the burning of the material between the marks specified in the standard test ${ }^{34}$.

\subsubsection{Spectroscopy analysis}

Fourier Transform Infrared Spectroscopy (FTIR) was carried out in a Cary 630 FTIR (Agilent Technologies) at a wave number range from 4000 to $600 \mathrm{~cm}^{-1}$ to investigate the influence of RC in the PLA structure before and after the flammability tests. Each infrared spectrum was the result of 32 scans at a resolution of $4 \mathrm{~cm}^{-1}$.

\subsubsection{Mechanical characterization}

Tensile tests were carried out in an Instron universal testing machine, model 5569, with a crosshead speed of $5 \mathrm{~mm} / \mathrm{min}$, testing $3 \mathrm{~mm}$ thick dumbbell-shaped specimens (type I) according to ASTM D638-1423 . Three-point bending tests were performed according to ASTM D790-1733 on rectangular specimens (dimensions of $126 \times 13 \times 3 \mathrm{~mm}$ ) using the same universal testing machine with a cell load of $50 \mathrm{kN}$ and span length of $51.2 \mathrm{~mm}$. Five specimens for each one of the compositions were tested during the tensile and three-point bending tests. 
Izod impact tests were carried out in a pendulum-type machine (RESIL 25, Ceast) with a pendulum of $1 \mathrm{~J}$ and using notched specimens in accordance to ASTM D256-10 $0^{36}$, ten specimens were tested for each composition studied.

\subsubsection{Statistical analysis}

The influence of the presence and content of $\mathrm{RC}$ on the mechanical properties of the composites was analyzed by one-way ANOVA (analysis of variance) and Tukey test, at a significance level of 0.05 .

\subsubsection{Morphology}

Scanning electron microscopy (SEM) was performed to investigate the surface morphology of cryofractured and impact tested specimens, dispersion of the clay in the matrix and interfacial adhesion between polymer/clay. The micrographs were obtained in a Philips XL30 FEG microscope operated at $10 \mathrm{kV}$; prior to observation, all the samples were sputter coated with gold.

\subsubsection{Thermal characterization}

The thermal stability of the samples was analyzed by thermogravimetry using a TGA Q50, from TA Instruments at a heating rate of $20^{\circ} \mathrm{C} / \mathrm{min}$, from room temperature up to $800{ }^{\circ} \mathrm{C}$, under a $100 \mathrm{ml} / \mathrm{min} \mathrm{N}_{2}$ flux.

The thermal properties of the injection molded samples were studied by differential scanning calorimetry using a DSC Q2000 (TA Instruments, USA), under $\mathrm{N}_{2}$ atmosphere and flux of $50 \mathrm{ml} / \mathrm{min}$, between 20 and $200{ }^{\circ} \mathrm{C}$ at $10^{\circ} \mathrm{C} / \mathrm{min}$. The degree of crystallinity $\left(\mathrm{X}_{\mathrm{c}}\right)$ of the PLA was calculated by Equation 2 :

$$
X_{c}=\left(\frac{\Delta H_{m}-\Delta H_{c c}}{\Delta H_{m}^{0} \times \phi_{i}}\right) \times 100
$$

where $\Delta \mathrm{H}_{\mathrm{m}}$ is the enthalpy of fusion directly obtained by DSC, $\Delta \mathrm{H}_{\mathrm{cc}}$ is the cold crystallization enthalpy, $\Delta H_{m}^{0}$ is the enthalpy of fusion of $100 \%$ crystalline polymer $\left(93 \mathrm{~J} / \mathrm{g}\right.$ for $\left.\mathrm{PLA}^{37}\right)$, and $\phi_{i}$ is the mass fraction of the PLA in the sample. DSC analysis was also used to investigate the influence of the addition of $\mathrm{RC}$ in the glass transition temperature $\left(\mathrm{T}_{\mathrm{g}}\right)$, cold crystallization temperature $\left(\mathrm{T}_{\mathrm{cc}}\right)$ and melting temperature $\left(\mathrm{T}_{\mathrm{m}}\right)$ of the samples.

\section{Results and Discussion}

\subsection{Flammability tests}

Vertical and horizontal UL94 burning tests were performed to identify self-extinguish behavior and burning rate, respectively, of the composites produced with respect to neat PLA. Regarding the HB test, pristine PLA got a $23.5 \mathrm{~mm} / \mathrm{min}$ linear burning rate, which is in accordance with the standard, allowing it to receive the $\mathrm{HB}$ rate. Both PLA and composites burned with drips and no charring at the surface was observed, however, for the composites, it was not possible to calculate the burning rate since during the test none of the specimens tested for each composition burned for enough time to reach the marks specified in the standard. From this observation, it could be seen that the addition of RC to the polymer matrix allowed a self-extinguish behavior for the composites, being an indicative that they could be rated according to vertical burning test that evaluates this kind of behavior.

Moreover, the $23.5 \mathrm{~mm} / \mathrm{min}$ burning rate for PLA can be understood as a low burning rate and is in accordance to other flame retardancy studies for this polymer ${ }^{38,39}$. PLA/RC composites did not show a superior burning rate with respect to neat PLA, differently from what is seen in the literature; instead, they presented a self-extinguish performance. Also, the flame extinction happened faster for the composites with higher clay content (10 and $15 \mathrm{wt} \%$ ) than for PLA/2.5RC, showing the greater influence of higher clay content on the flame extinction behavior of the material.

For the UL 94 vertical burning test, PLA and composites showed self-extinction of the flame, the mean after-flame times $\left(t_{1}\right.$ and $\left.t_{2}\right)$ are presented in Table 1 along with some qualitative information from the test observation and the material rating. No after-glowing time was observed neither for neat PLA nor PLA/RC composites, also none of them burned up to the holding clamp.

From literature, a common trend was observed in which PLA/clay composites tend to have higher burning times than neat PLA or very close to the pure polymer ${ }^{38,40,41}$, being high enough to prevent them from being rated according UL 94V criteria. For the present research, that trend was not observed, on the contrary, all PLA/RC composites had after-flame times $\left(t_{1}\right.$ and $\left.t_{2}\right)$ lower than for the reference material and all of them (including neat PLA) received the V-2 classification. No better rate was given to the composites because all of them presented flame dripping causing the ignition of the cotton indicator. Even though a better classification could not be reached, a successful result in terms of flammability was achieved once the composites showed self-extinguish behavior and reduced burning times with respect to PLA.

It is important to point out that during both vertical and horizontal burning tests, all the samples showed a vigorous bubbling while burning. This characteristic comes from the burning process of PLA from which the degradation products of the polymer are responsible for forming rising

Table 1. Vertical burning test UL 94V results for PLA and PLA/RC composites.

\begin{tabular}{|c|c|c|c|c|c|}
\hline \multirow{2}{*}{ Sample } & \multicolumn{2}{|c|}{ After flame time (s) } & \multirow{2}{*}{ Flame dripping } & \multirow{2}{*}{ Cotton ignition } & \multirow{2}{*}{ Rating } \\
\hline & First application $\left(\mathrm{t}_{1}\right)$ & Second application $\left(\mathrm{t}_{2}\right)$ & & & \\
\hline PLA & $15 \pm 4$ & $12 \pm 8$ & Yes & Yes & $\mathrm{V}-2$ \\
\hline $\mathrm{PLA} / 2.5 \mathrm{RC}$ & $8 \pm 2$ & $2 \pm 1$ & Yes & Yes & $\mathrm{V}-2$ \\
\hline PLA/10RC & $10 \pm 3$ & $7 \pm 6$ & Yes & Yes & $\mathrm{V}-2$ \\
\hline PLA/15RC & $12 \pm 2$ & $4 \pm 2$ & Yes & Yes & $\mathrm{V}-2$ \\
\hline
\end{tabular}


bubbles that allow the transportation of the clay particles to the surface of the composite ${ }^{40,42,43}$. From this phenomenon, since dripping still occurred while burning, it is believed that a discontinuous ceramic-like protective layer was formed at the material surface by the deposition of clay particles on it.

The presence of this layer is an explanation for the reduced burning times of the composites as the accumulation at the layer was of a highly refractory clay that withstands high temperatures and that acted as a physical mechanism against the combustion process, preventing the polymer from burning for longer times and allowing the self-extinguish behavior of the composites.

\subsection{FTIR}

FTIR analyses were performed on PLA and PLA/RC composites to investigate the chemical composition of the materials surface before and after flammability tests as shown in Figure 1. From FTIR spectrum for neat PLA and composites before the burning test, Figure 1a, it could be seen the typical bands of pure PLA on the range from 800 to $1500 \mathrm{~cm}^{-1}$ assigned mainly to $\mathrm{C}, \mathrm{H}$ and $\mathrm{O}$ bonds vibrations, and also the band at $1748 \mathrm{~cm}^{-1}$ related to the carbonyl ester groups of PLA ${ }^{38}$. Regarding the composites, the same bands of PLA were seen on the PLA/RC spectra, however a decrease in intensity was observed when comparing to neat PLA. Moreover, as RC was incorporated to the material, specific bands assigned to the clay appeared for the composites at low intensities, namely: $800 \mathrm{~cm}^{-1}$ corresponding to $\mathrm{Si}-\mathrm{O}$ stretching or Si-O-Al stretching, a band at $911 \mathrm{~cm}^{-1}$ was also observed, being related to Al-OH stretching vibration and a band at $3454 \mathrm{~cm}^{-1}$ related to $\mathrm{H}-\mathrm{O}-\mathrm{H}$ stretching of water of hydration ${ }^{20,44}$.

Regarding FTIR spectra for the materials after burning, Figure 1b, it was observed that as RC content increased on the composite, the bands related to PLA disappeared and it was observed for PLA/10RC and PLA/15RC two main bands of very low intensities at 800 and $3739 \mathrm{~cm}^{-1}$, assigned to $\mathrm{Si}-\mathrm{O} / \mathrm{Si}-\mathrm{O}-\mathrm{Al}$ stretching, and hydroxyl groups, respectively ${ }^{19,20,44}$. The existence of these bands once more points out to the presence of a discontinuous ceramic-like layer on the composites surface; besides, the lack of PLA signal indicates that no residual polymer fractions are on the surface after burning corroborating to the hypothesis that a physical barrier was present at the surface of the material.

\subsection{Mechanical characterization}

The mechanical behavior of the materials is displayed in Figure 2 as function of the RC content in the samples. A continuous increase was observed for both Young's and flexural modules as higher contents of clay were added to the composites. As for the Young's modulus, Figure 2a, the composite with $15 \mathrm{wt} \%$ of RC showed a $25 \%$ increase when compared to neat PLA (4.21 GPa and 3.37 GPa, respectively). Similar trends were also observed in other studies of PLA composites with different clays ${ }^{29,38,45}$; in these cases, the clay content was kept at very low weight percentage ratios and improvements in the elastic modulus was still reached. A plausible explanation for Young's modulus improvement could be related to the high modulus of the ceramic materials, leading to the improvement of this property for the composites; also a good dispersion of the clay particles in the polymer matrix may have played an important role for the reinforcement ${ }^{46}$. Regarding the degree of improvement reached for the Young's modulus, Stoclet and coworkers ${ }^{45}$ pointed out that clays with high surface areas tend to show higher stiffness improvements at lower clay weight contents.

According to Figure 2a and the stress-strain curves presented in Figure 3, no reinforcement for tensile strength was observed with respect to the addition of $\mathrm{RC}$ to the polymer. However, the observed decrease was only $12 \%$ when comparing neat PLA and PLA/15RC (53.41 and 47.51 $\mathrm{MPa}$, respectively), which is a good indication that the interfacial adhesion between polymer and clay was not so week without modifying the clay surface.

With the increase in stiffness, the brittleness of the PLA/RC composites also increased slightly since the addition of RC led to a decrease in elongation at break (Figure $2 \mathrm{~b}$ and Figure 3). A similar trend was also observed by Kontou and coworkers $^{46}$ for PLA/MMT composites, however in the present study, the composite with higher RC content (15 wt $\%$ ) had a $46 \%$ decrease in elongation at break compared to neat PLA while PLA/MMT with $5 \mathrm{wt} \%$ of organically
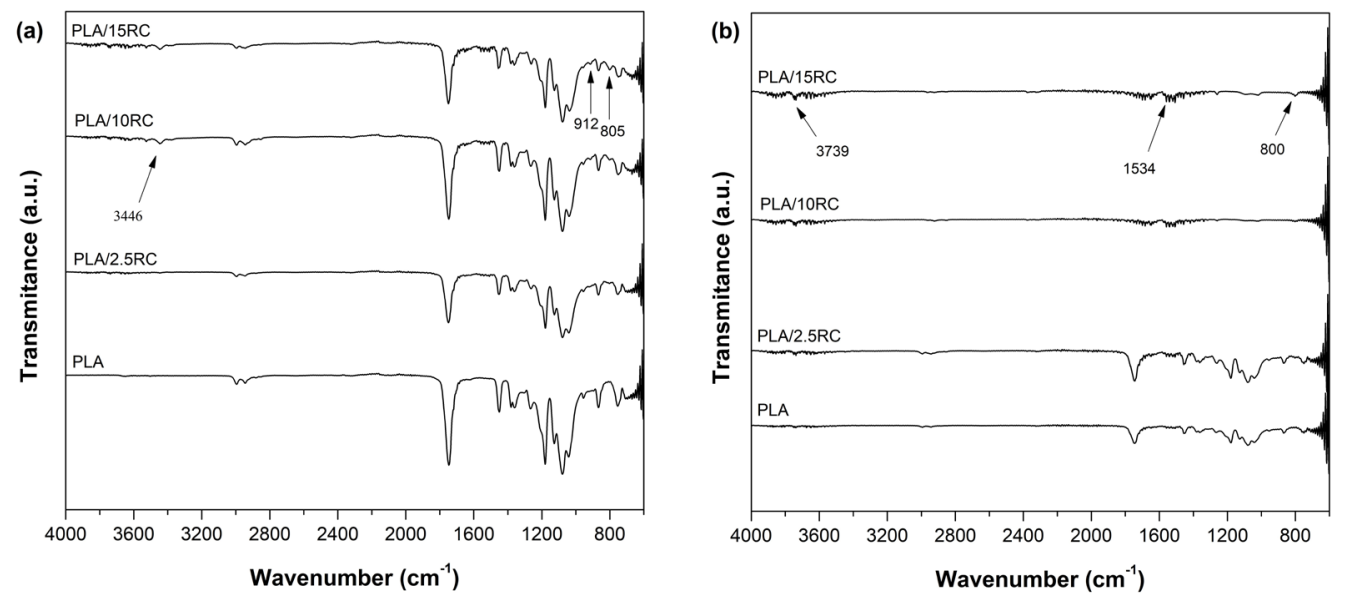

Figure 1. FTIR spectra for neat PLA and PLA/RC composites (a) before and (b) after burning tests. 
(a)

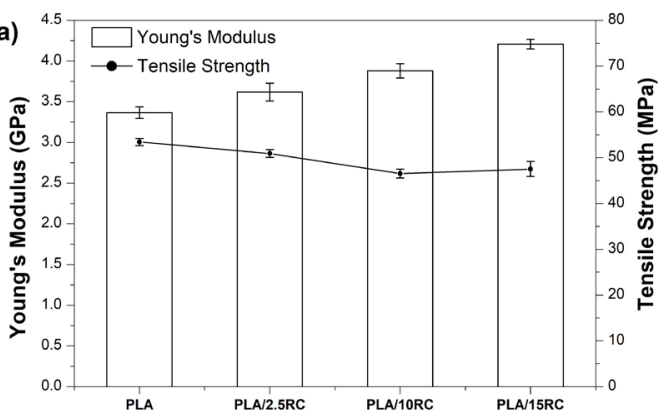

(c)

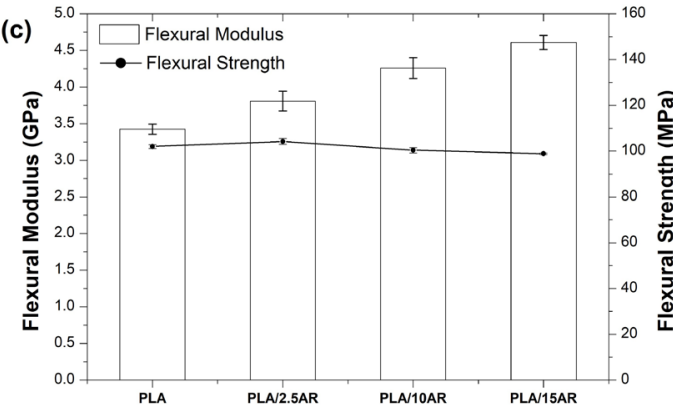

Figure 2. Mechanical behavior of neat PLA and PLA/RC composites: (c) flexural modulus and strength, (d) impact strength.

modified clay in the study by Kontou and coworkers showed a comparable reduction of $43 \%{ }^{46}$. Again, this difference may be an indication that the interfacial adhesion between RC and PLA was not so poor when comparing to studies that use organically modified clays.

Flexural modulus, Figure 2c, showed the same trend observed for Young's modulus, i.e., it increased as clay was added to the composite. However, the flexural strength improved slightly for PLA/2.5RC followed by a decrease in strength as the clay content increased; despite this reduction in flexural strength, composites with 10 and $15 \mathrm{wt} \%$ of clay showed remarkably similar results, 98.15 and $97.72 \mathrm{MPa}$, respectively.

The incorporation of $\mathrm{RC}$ to the polymer matrix promoted a slight reinforcement for the notched impact strength of the composites. Compared to pure PLA, Figure 2d, all the composites had an increase in strength from about $26 \mathrm{~J} / \mathrm{m}$ to $28 \mathrm{~J} / \mathrm{m}$, indicating that, although the clay content changes, no negative influence is observed. This is an unusual behavior for composites with high contents of unmodified fillers since the tendency for agglomeration favors the reduction of impact properties. Guo et al. ${ }^{47}$ evaluated the effect of different types of clays (natural and organophilic montmorillonite, halloysite nanotubes) on the mechanical properties of PLA composites, adding clays' contents from 1 up to $15 \mathrm{wt} \%$. For all composites the impact resistance was reduced when compared to pure PLA, and the higher the clay content, the lower the impact strength. The authors indicated that the clay particles could generate internal stresses, resulting in local crack formation, even when the montmorillonite was exfoliated through the PLA matrix. Thus, the results obtained for the PLA/RC composites in this work must be highlighted.
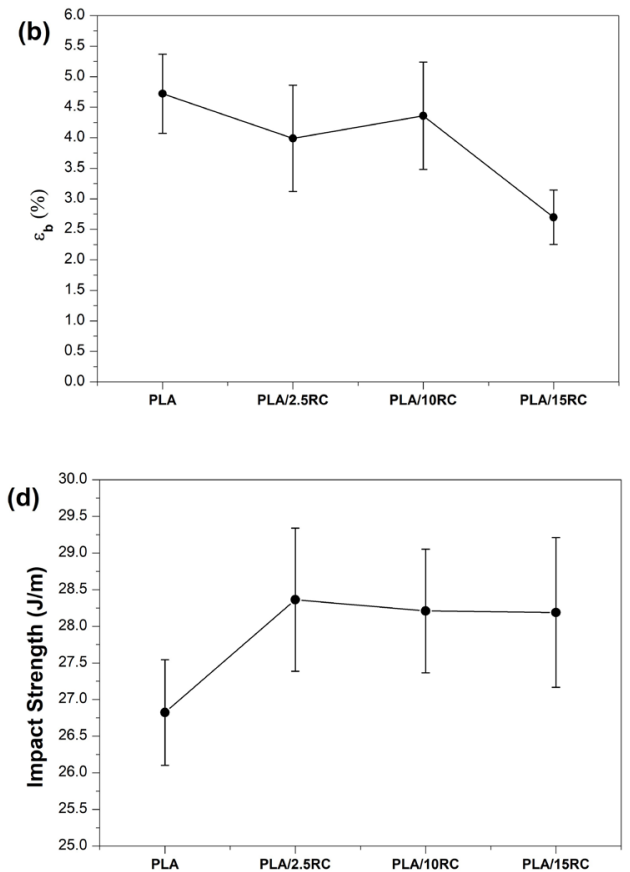
(a) Young's modulus and tensile strength, (b) elongation at break,

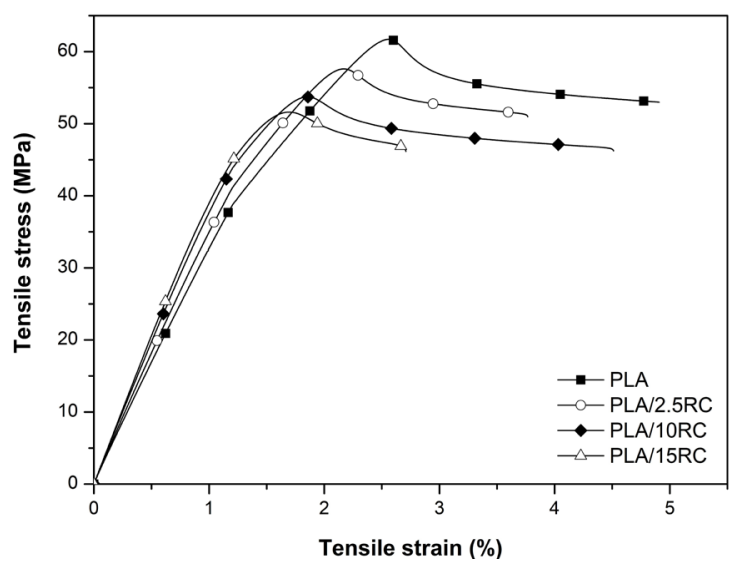

Figure 3. Stress-strain curves for PLA and PLA/RC composites.

\subsection{ANOVA}

From ANOVA results, presented in Table 2, it was observed that for all the mechanical properties studied the Prob-F was lower than the significance level; this result indicates that at least two compositions had means significantly different. Besides, the R-square corresponds to the coefficient of determination ${ }^{48}$ and it explains the variability in mechanical properties caused by the clay content; thus, the addition of different clay contents was responsible for approximately $88 \%, 95 \%, 57 \%$ and $35 \%$ in the variation of tensile strength, Young's modulus, elongation at break and impact strength of the composites, respectively. 
Table 2. Main ANOVA results for the mechanical properties studied.

\begin{tabular}{|c|c|c|c|c|c|c|c|}
\hline $\begin{array}{c}\text { Mechanical } \\
\text { property }\end{array}$ & $\begin{array}{l}\text { Source of } \\
\text { Variation }\end{array}$ & $\begin{array}{l}\text { Degree of } \\
\text { Freedom }\end{array}$ & $\begin{array}{l}\text { Sum of } \\
\text { squares }\end{array}$ & Mean square & F-value & Prob-F & R-square \\
\hline \multirow{3}{*}{$\begin{array}{l}\text { Tensile } \\
\text { strength }\end{array}$} & Clay-wt\% & 3 & 150.10 & 50.033 & 40.31 & $1.10 \mathrm{E}-7$ & 0.88315 \\
\hline & Error & 16 & 19.86 & 1.241 & - & - & - \\
\hline & Total & 19 & 169.96 & - & - & - & - \\
\hline \multirow{3}{*}{$\begin{array}{l}\text { Young's } \\
\text { Modulus }\end{array}$} & Clay-wt $\%$ & 3 & 1.95 & 0.649 & 92.85 & $2.47 \mathrm{E}-10$ & 0.94568 \\
\hline & Error/Residual & 16 & 0.11 & 0.007 & - & - & - \\
\hline & Total & 19 & 2.06 & - & - & - & - \\
\hline \multirow{3}{*}{$\begin{array}{l}\text { Elongation at } \\
\text { break }\end{array}$} & Clay-wt $\%$ & 3 & 11.66 & 3.886 & 7.21 & $2.82 \mathrm{E}-3$ & 0.57464 \\
\hline & Error & 16 & 8.63 & 0.539 & - & - & - \\
\hline & Total & 19 & 20.29 & - & - & - & - \\
\hline \multirow{3}{*}{$\begin{array}{l}\text { Impact } \\
\text { Strength }\end{array}$} & Clay-wt $\%$ & 3 & 15.54 & 5.18 & 6.42 & $1.35 \mathrm{E}-3$ & 0.34843 \\
\hline & Error & 36 & 29.07 & 0.81 & - & - & - \\
\hline & Total & 39 & 44.61 & - & - & - & - \\
\hline
\end{tabular}
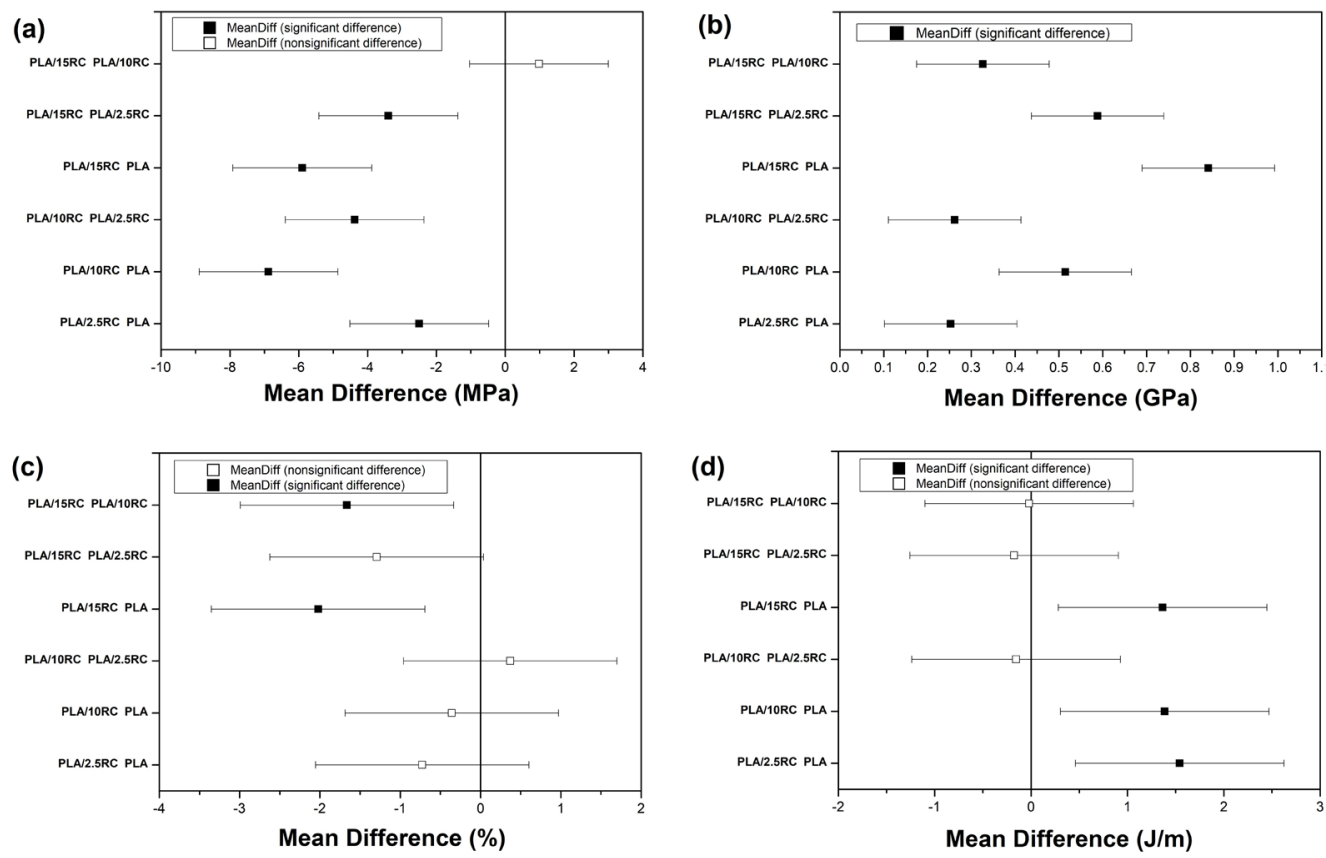

Figure 4. Means Comparison using Tukey Test for: (a) Tensile strength, (b) Young's Modulus, (c) Elongation at break, (d) Impact strength.

Tukey test was performed to determine which composites were different from each other. Figure 4 shows the means difference using the Tukey test, it also shows, in black, the compositions which the means difference was significant at the 0.05 level.

For tensile strength (Figure $4 \mathrm{a}$ ) it was observed that only the composites PLA/10RC and PLA/15RC had a nonsignificant difference between their means; indicating that higher clay loads did not bring statistically different results in performance for the two compositions. According to Figure $4 b$, all the means comparisons had a significant difference, as it was previously discussed, the increase in clay content led to a continuous increase for the Young's modulus, which was confirmed to the high R-square found for this analysis. Comparing the means difference for the elongation at break results, Figure $4 \mathrm{c}$, it was observed that up to $10 \mathrm{wt} \%$ of clay, no statistical difference occurred for the materials; however, increasing the clay content to $15 \mathrm{wt} \%$ promoted a statistically significant difference between PLA-PLA/15RC and among PLA/10RC-PLA/15RC, which led to an increase in brittleness when comparing to neat PLA and also the composites with higher clay loads. From Tukey test results for impact strength, Figure 4d, it was observed no statistical significant difference between the composites means. The statistical difference occurred only when comparing composites to pure PLA, indicating that the incorporation of different clay contents did not have great influence on the impact strength of the composites, which was also already pointed out by the low R-square (35\%) found; however, it also did not generate losses in performance for the composites.

From the ANOVA and Tukey test results, it is concluded that incorporation of higher clay loads (i.e. 10 to $15 \mathrm{wt} \%$ ) did not promote considerable losses on the composites performance. These results must be highlighted since the 
higher the $\mathrm{RC}$ content the lesser will be the price of the composite when compared to PLA.

\subsection{Morphology}

Morphology of PLA and PLA/RC composites was investigated by SEM to determine the extent of the clay dispersion in the composites. SEM micrographs of PLA and composites cryofractured surfaces are presented in Figure 5. Comparing to neat PLA (Figure 5a), SEM investigations show that the composites appear to have a good and homogeneous distribution of filler, RC, into the polymer matrix (Figure 5b-c). In addition, the micrographs showed few larger particles (typical of the particle size distribution of the clay) and/or small agglomerates (Figure 5d), with noticeable interface heterogeneity among polymer/clay.

Even though few larger particles/agglomerates (indicated by the red arrows in the micrographs) are present within the polymer, the overall clay dispersion on the matrix was positive; from that, one may suggest that the compatibility between RC and PLA was not so weak, contributing to a better interfacial adhesion between PLA and the dispersed phase, when compared to other types of clay used in PLA/ clay studies.

From impact surface micrographs, Figure 6, it could be seen once more the good dispersion of $\mathrm{RC}$ into the polymer matrix (Figure 6b-d), the presence of some larger particles/agglomerates (Figure 6c) and voids resulting from the detachment of particles from the polymer matrix, Figure 6d, also pointed by the red arrows in the micrographs.

It is important to emphasize that in the present study higher clay contents were employed (10-15 wt\%) and that no previous surface treatment of RC particles to make them more compatible with PLA was employed, therefore the ability of RC to evenly disperse within PLA was impressive.

\subsection{Thermal characterization}

Thermal stability of PLA and PLA/RC composites was evaluated by thermogravimetric analysis (TGA). Table 3 summarizes the data for the degradation temperatures for all the compositions studied and Figure 7 shows the TGA and DTG curves for PLA, RC and all the composites studied.
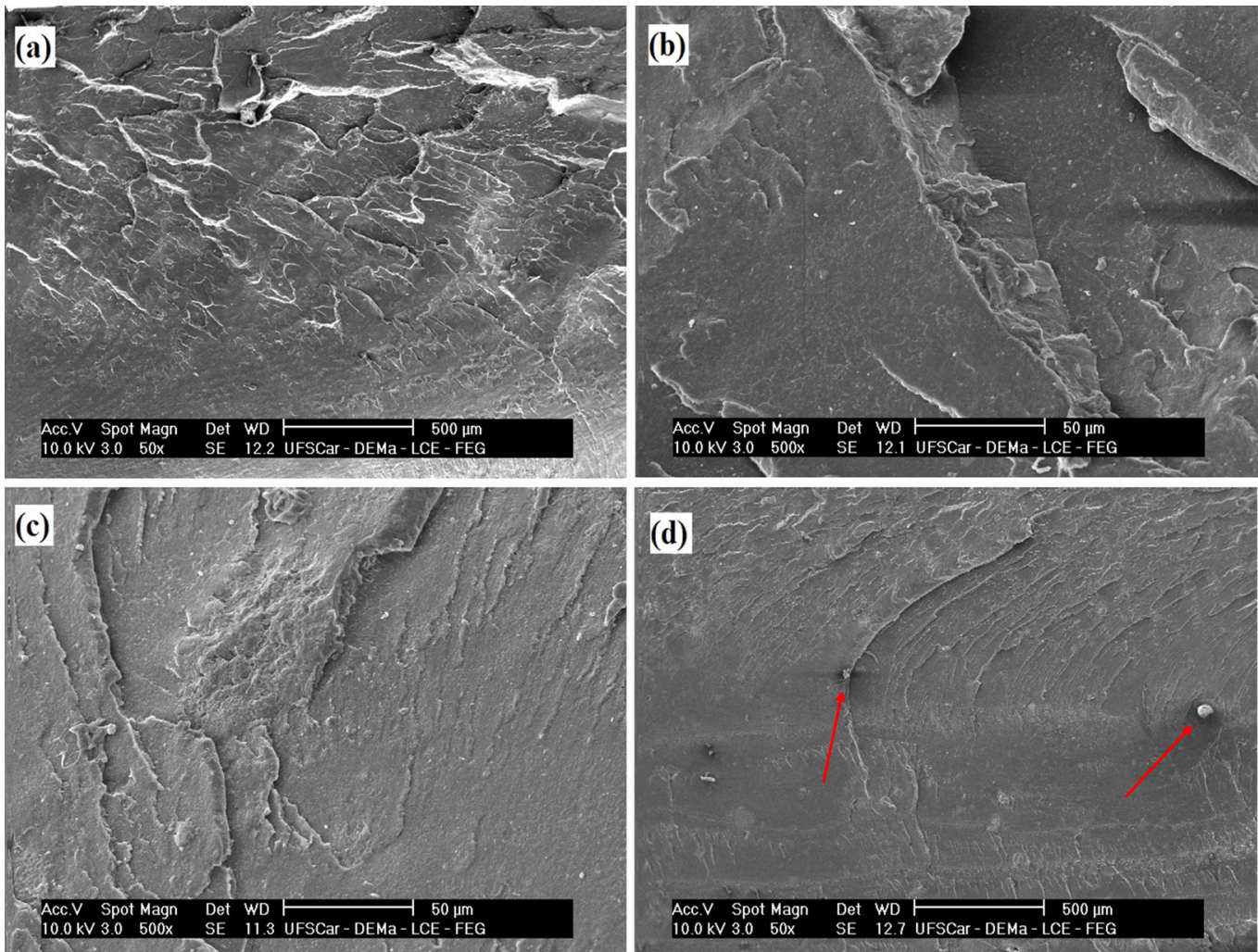

Figure 5. Cryofractured surface SEM micrographs: (a) PLA, (b) PLA/2.5RC, (c) PLA/10RC, (d) PLA/15RC.

Table 3. Thermal degradation parameters of the injection molded samples obtained by TGA.

\begin{tabular}{ccccc}
\hline Sample & $\mathrm{T}_{\text {onset }}\left({ }^{\circ} \mathrm{C}\right)$ & $\mathrm{T}_{\text {peak }}\left({ }^{\circ} \mathrm{C}\right)$ & $\mathrm{T}_{\text {endset }}\left({ }^{\circ} \mathrm{C}\right)$ & Residue at $750^{\circ} \mathrm{C}(\%)$ \\
\hline PLA & 352 & 373 & 397 & 0.2 \\
\hline PLA/2.5RC & 337 & 366 & 394 & 2.7 \\
\hline PLA/10RC & 327 & 354 & 387 & 8.8 \\
\hline PLA/15RC & 326 & 354 & 383 & 12.7 \\
\hline
\end{tabular}



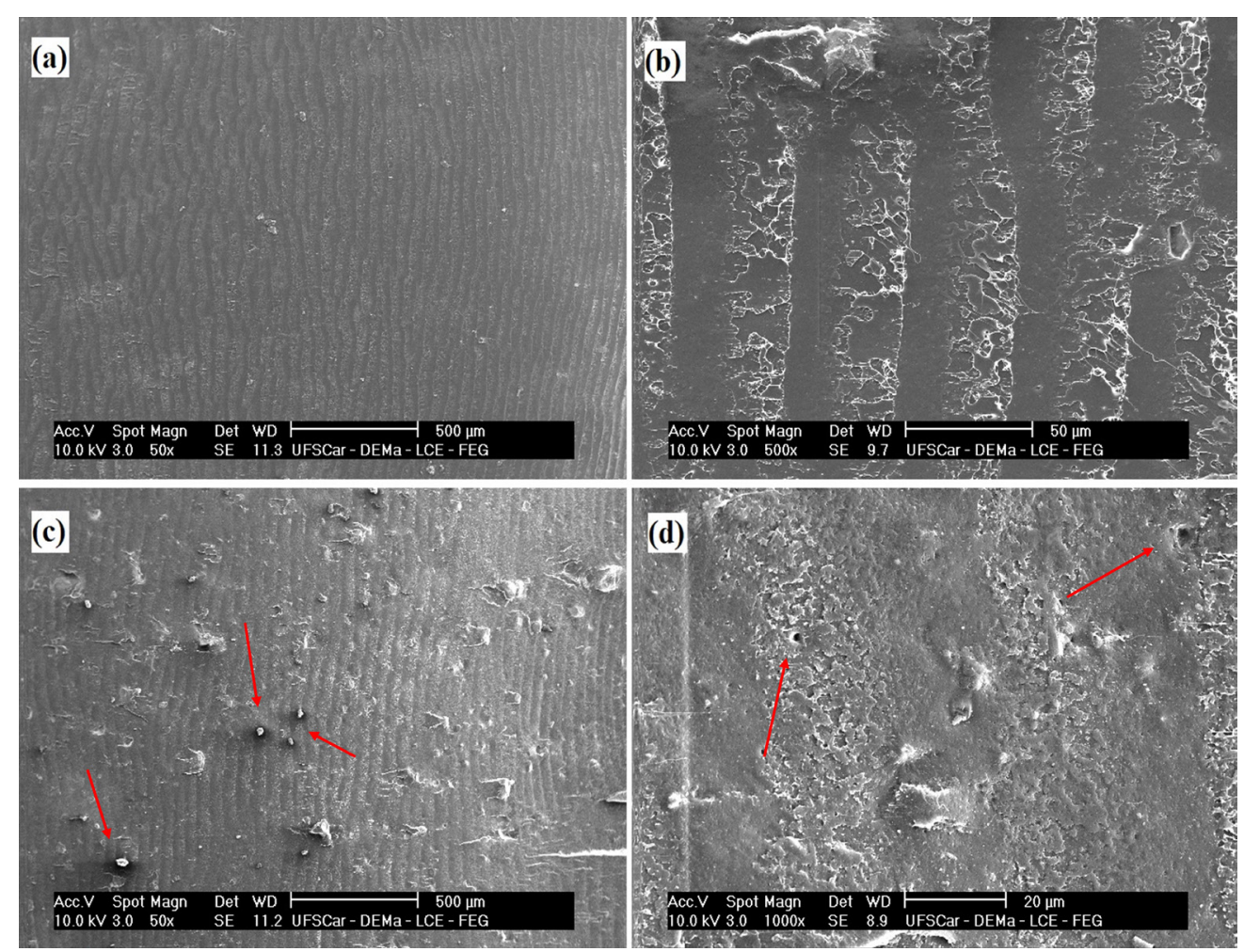

Figure 6. Impact surface SEM micrographs: (a) PLA, (b) PLA/2.5RC, (c) PLA/10RC, (d) PLA/15RC.
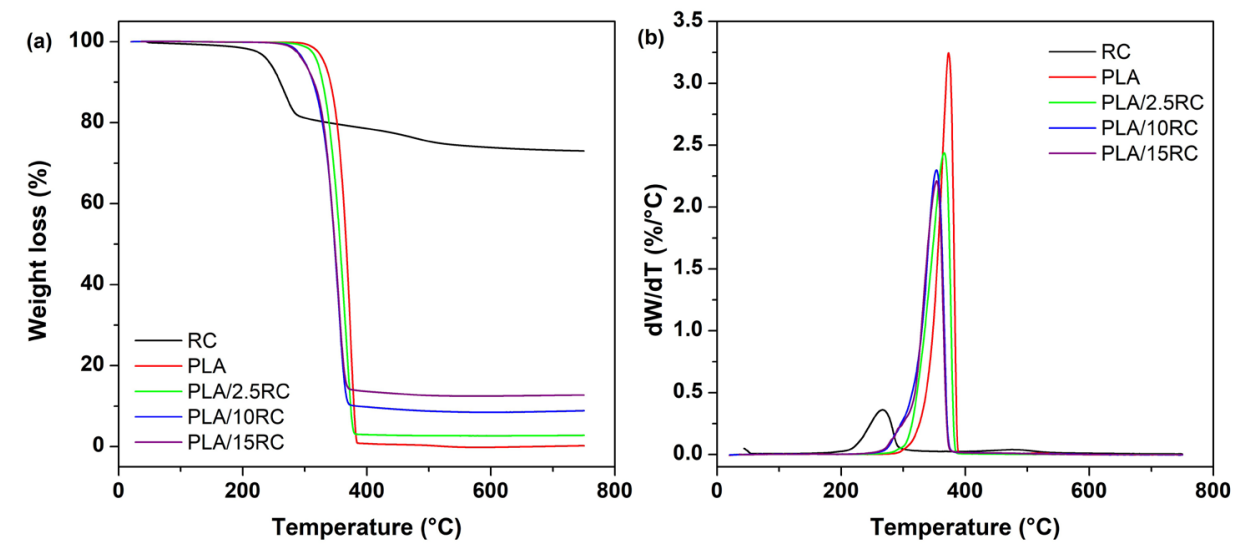

Figure 7. (a) Thermogravimetric analysis of RC and injection molded samples, (b) DTG curves of RC and injection molded samples.

The refractory clay exhibits an onset degradation temperature $\left(\mathrm{T}_{\text {onset }}\right)$ about $235^{\circ} \mathrm{C}$ with a three-step mass loss, Figures $7 \mathrm{a}-\mathrm{b}$, corresponding to structural water release from the RC structure and to water release from the organic matter, dehydroxylation reaction and pyrolysis and combustion of organic matter ${ }^{21}$. Differently from the RC, PLA has only one degradation step (Figure $7 \mathrm{a}-\mathrm{b}$ ) with $\mathrm{T}_{\text {peak }}$ about $373^{\circ} \mathrm{C}$ and corresponds to cleavage of bonds on the polymer backbone leading to the release of gaseous products such as cyclic oligomers, acetaldehyde, lactide and carbon monoxide ${ }^{40}$. Similarly to PLA, all the composites also showed one-step mass loss (Figure 7b).
TGA also showed that the addition of RC to PLA matrix did not improve the thermal stability of the composites once all of them presented a continuous decrease for the degradation temperatures. However, one may consider that this reduction was not of great significance given that higher clay contents (up to $15 \mathrm{wt} \%$ ) were added to the polymer matrix and the maximum decrease reached for $\mathrm{T}_{\text {onset }}$ was around $7 \%$ for the composites with the highest $\mathrm{RC}$ content with respect to neat PLA. Furthermore, it could be noticed that as the clay content increased, the reduction in the degradation temperatures became less pronounced. Regarding the residue present at the end of the decomposition process, it was noticeable that 
Table 4. Thermal parameters of the injection molded samples obtained by DSC (first heating cycle).

\begin{tabular}{cccccc}
\hline Sample & $\mathrm{T}_{\mathrm{g}}\left({ }^{\circ} \mathrm{C}\right)$ & $\mathrm{T}_{\mathrm{cc}}\left({ }^{\circ} \mathrm{C}\right)$ & $\mathrm{T}_{\mathrm{m}}\left({ }^{\circ} \mathrm{C}\right)$ & $\left(\Delta H_{m}-\Delta H_{c c}\right)(\mathrm{J} / \mathrm{g})$ & $\mathrm{X}_{\mathrm{c}}(\%)$ \\
\hline PLA & 62 & 110 & $149 / 155$ & 3.55 & 3.8 \\
\hline PLA/2.5RC & 62 & 108 & $149 / 155$ & 2.95 & 3.2 \\
\hline PLA/10RC & 60 & 100 & $148 / 154$ & 1.85 & 2.2 \\
\hline PLA/15RC & 60 & 106 & $149 / 154$ & 3.60 & 4.5 \\
\hline
\end{tabular}

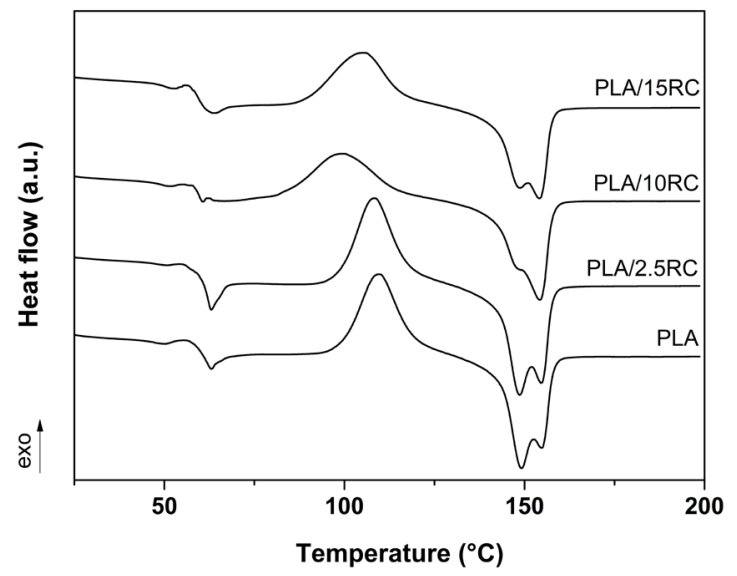

Figure 8. First heating DSC curves of the injection molded samples.

total degradation of the composites did not occur, this fact is explained by the presence of the highly refractory clay in the composites, which resists to high temperatures and does not have total decomposition during the tests.

DSC analysis was performed to determine the influence of RC in the $\mathrm{T}_{\mathrm{g}}, \mathrm{T}_{\mathrm{cc}}, \mathrm{T}_{\mathrm{m}}$ and crystallinity of the composites. It must be noted that for the purposes of this research only the data from the first heating cycle was presented because it is this cycle that gives the information regarding the structure obtained from the injection molding process. As shown in the DSC curves (Figure 8) and summarized in Table 4, the glass transition temperature for pure PLA and for the composites did not show relevant changes; even the composites with higher clay content showed glass transition temperature inside the range specified by the polymer manufacturer.

As for the cold crystallization temperature, it was observed a slight shift towards lower temperatures from neat PLA to the composites; regarding the melting temperature, it was observed double peaks for the melting endotherms, this is explained by the melting of the crystallites of different sizes and/or the quality of ordering ${ }^{49,50}$. The data obtained with respect to the crystallinity of the materials show that the incorporation of $\mathrm{RC}$ to the polymer matrix did not have a pronounced effect on this property; this result can be implied by the fact that the difference between the enthalpies was small indicating that no greater effect on crystallinity was promoted by the refractory clay (all composites kept very low percentages of crystallinity).

Therefore, TGA and DSC measurements pointed out that the incorporation of different clay contents to PLA did not affect the overall thermal properties of the final material produced, even at a higher clay content.

\section{Conclusions}

The effects of highly refractory clay (RC) on thermal, mechanical and flammability properties of PLA composites have been investigated. PLA/RC showed good processability comparing to unfilled PLA. TGA and DSC characterization demonstrated that the clay addition in the polymer matrix did modify the overall thermal stability of the material.

From mechanical results and ANOVA analysis, it is clear that the incorporation of refractory clay to PLA matrix did not promote significant negative influence on the final properties of the composites produced. No regular trend on reinforcement was observed for the mechanical properties; tensile/flexural strength and strain presented a decrease compared to pristine PLA while Young's modulus and impact strength had an increase, which was more prominent for the elastic modulus. The statistical analysis confirmed that no significant difference was observed among the composites with higher clay loads, suggesting that the incorporation of $\mathrm{RC}$ to the polymer matrix may be satisfactory on the cost reduction of the final material.

Regarding the flammability of the samples, the addition of clay to PLA led to successful results in terms of selfextinguish behavior, with all the composites being rated as $\mathrm{V}-2$ for the vertical burning test. As for the horizontal test, the burning rate for PLA/RC composites could not be determined because the flame extinguished before the standard measurements could even start; confirming once more the self-extinguish behavior of the material which was suggested to be due to the presence of a discontinuous ceramic-like layer on the composite surface after burning. Further studies must be conducted to investigate the dripping behavior of the composites to achieve even better flammability classifications.

It must be pointed out that the clay did not receive any surface treatment to improve its compatibility with the polymer matrix, and still, good mechanical and fire properties were achieved; these results were mostly attributed to the high refractoriness of the clay and to its good dispersion throughout the polymer matrix.

\section{Acknowledgments}

This work was supported by the Coordenação de Aperfeiçoamento de Pessoal de Nível Superior, Brasil (CAPES) [Finance Code 001] and Conselho Nacional de Desenvolvimento Científico e Tecnológico (CNPq, Process 
427639/2016-6). The authors are also grateful to Prof. Lidiane Cristina Costa (DEMa/UFSCar) for kindly donating the PLA and to the technicians and other staff members from UNIFAL and UFSCar for the support and help during this research.

\section{References}

1. Sun CB, Mao HD, Chen F, Fu Q. Preparation of polylactide composite with excellent flame retardance and improved mechanical properties. Chin J Polym Sci. 2018;36:1385-93.

2. Tawiah B, Yu B, Fei B. Advances in flame retardant poly(lactic acid). Polymers. 2018;10:876.

3. Murariu M, Dubois P. PLA composites: from production to properties. Adv Drug Deliv Rev. 2016;107:17-46.

4. Chow WS, Teoh EL, Karger-Kocsis J. Flame retarded poly(lactic acid): a review. Express Polym Lett. 2018;12:396-417.

5. Huang Y, Mei L, Chen X, Wang Q. Recent developments in food packaging based on nanomaterials. Nanomaterials. 2018;8:830-58.

6. Standau T, Zhao C, Castellón SM, Bonten C, Altstadt V. Chemical modification and foam processing of polylactide (PLA). Polymers. 2019;11:306

7. Kalendova A, Smotek J, Stloukal P, Kracalik M, Slouf M, Laske S. Transport properties of poly(lactic acid)/clay nanocomposites. Polym Eng Sci. 2019;59:2498-501.

8. Maqsood M, Seide G. Improved thermal processing of polylactic acid/oxidized starch composites and flame-retardant behavior of intumescent non-wovens. Coatings. 2020;10:291-310.

9. Alves JL, Rosa PTV, Realinho V, Antunes M, Velasco JI, Morales AR. Influence of chemical composition of Brazilian organoclays on the morphological, structural and thermal properties of PLA-organoclay nanocomposites. Appl Clay Sci. 2019; 180:105186

10. Ramesh P, Prasad BD, Narayana KL. Influence of montmorillonite clay content on thermal, mechanical, water absorption and biodegradability properties of treated kenaf fiber/ PLA-hybrid biocomposites. Silicon. 2021;13:109-18.

11. Lambert S, Wagner M. Environmental performance of biobased and biodegradable plastics: the road ahead. Chem Soc Rev. 2017;46:6855-71.

12. Malkappa K, Bandyopadhyay J, Ray SS. Thermal degradation characteristic and flame retardancy of polylactide-based nanobiocomposites. Molecules. 2018;23:2648-62.

13. Gallo JB, Agnelli JAM. Aspectos do comportamento de polímeros em condições de incêndio. Polímeros. 1998;8:23-38.

14. Laoutid F, Bonnaud L, Alexandre M, Lopez-Cuesta JM, Dubois P. New prospects in flame retardant polymer materials: from fundamentals to nanocomposites. Mater Sci Eng Rep. 2009;63:100-25

15. Wang X, Kalali EN, Wan JT, Wang DY. Carbon-family materials for flame retardant polymeric materials. Prog Polym Sci. 2017;69:22-46.

16. Jin X, Gu X, Chen C, Tang W, Li H, Liu X, et al. The fire performance of polylactic acid containing a novel intumescent flame retardant and intercalated layered double hydroxides. $\mathrm{J}$ Mater Sci. 2017;52:12235-50.

17. Sypaseuth FD, Gallo E, Çiftci S, Schartel B. Polylactic acid biocomposites: approaches to a completely green flame retarded polymer. e-Polymers. 2017; 17(6):449-62.

18. Uddin F. Clays, nanoclays, and montmorillonite minerals. Metall Mater Trans, A Phys Metall Mater Sci. 2008;39:2804-14.

19. Madejová J. FTIR techniques in clay mineral studies. Vib Spectrosc. 2003;31:1-10.

20. Nayak PS, Singh BK. Instrumental characterization of clay by XRF, XRD and FTIR. Bull Mater Sci. 2007;30:235-8.

21. Santos PS. Tecnologia de argilas aplicada às argilas brasileiras. São Paulo: Edgard Blucher; 1975.
22. Murray HH. Traditional and new applications for kaolin, smectite, and palygorskite: a general overview. Appl Clay Sci. 2000; 17:207-21

23. Zhang R, Xiao X, Tai Q, Huang H, Yang J, Hu Y. The effect of different organic modified montmorillonites (OMMTs) on the thermal properties and flammability of PLA/MCAPP/lignin systems. J Appl Polym Sci. 2013;127:4967-73.

24. Torabi H, Saadatabadi AR. Property investigation of poly(ethylene co-vinyl acetate)/poly (1-lactic acid)/organo clay nanocomposites. J Polym Environ. 2019;27:2886-94.

25. Tham WL, Poh BT, Ishak ZAM, Chow WS. Thermal behaviors and mechanical properties of halloysite nanotube-reinforced poly (lactic acid) nanocomposites. J Therm Anal Calorim. 2014;118:1639-47.

26. Tang G, Deng D, Chen J, Zhou K, Zhang H, Haung X, et al. The influence of organo-modified sepiolite on the flame-retardant and thermal properties of intumescent flame-retardant polylactide composites. J Therm Anal Calorim. 2017;130:763-72.

27. González-Ausejo J, Gámez-Pérez J, Balart R, Lagarón JM, Cabedo L. Effect of the addition of sepiolite on the morphology and properties of melt compounded PHBV/PLA blends. Polym Compos. 2019;40:E156-68.

28. Hapuarachchi TD, Peijs T. Multiwalled carbon nanotubes and sepiolite nanoclays as flame retardants for polylactide and its natural fibre reinforced composites. Compos, Part A Appl Sci Manuf. 2010;41:954-63.

29. Matusik J, Stodolak E, Bahranowski K. Synthesis of polylactide/ clay composites using structurally different kaolinites and kaolinite nanotubes. Appl Clay Sci. 2011;51:102-9.

30. Narmon AS, Dewaele A, Bruyninckx K, Sels BF, Puyvelde PV, Dusselier M. Boosting PLA melt strength by controlling the chirality of co-monomer incorporation. Chem Sci. 2021;12:567281.

31. Maestrelli SC, Roveri CD, Nunes AGP, Faustino LM, Aielo GF, Pinto LPA, et al. Estudo de caracterização de argilas não plásticas da região de Poços de Caldas, MG. Ceramica. 2013;59:242-8.

32. ASTM: American Society for Testing and Materials. ASTM D638-14 - Standard test method for tensile properties of plastics. West Conshohocken: ASTM International; 2014. p. 1-17.

33. ASTM: American Society for Testing and Materials. ASTM D790-17 - Standard test method for flexural properties of unreinforced and reinforced plastics and electrical insulation materials. West Conshohocken: ASTM International; 2017. p. $1-11$.

34. ASTM: American Society for Testing and Materials. ASTM D635-18 - Standard test method for rate of burning and/or extent and time of burning of plastics in a horizontal position 1. West Conshohocken: ASTM International; 2018. p. 1-8.

35. ASTM: American Society for Testing and Materials. ASTM D3801-19 - Standard test method for measuring the comparative burning characteristics of solid plastics in a vertical position 1 . West Conshohocken: ASTM International; 2019. p. 1-7.

36. ASTM: American Society for Testing and Materials. ASTM D256-10 - Standard test methods for determining the Izod pendulum impact resistance of plastics. West Conshohocken: ASTM International; 2018. p. 1-20.

37. Harris AM, Lee EC. Improving mechanical performance of injection molded PLA by controlling crystallinity. J Appl Polym Sci. 2007;107:2246-55.

38. Fukushima K, Murariu M, Camino G, Dubois P. Effect of expanded graphite/layered-silicate clay on thermal, mechanical and fire retardant properties of poly(lactic acid). Polym Degrad Stabil. 2010;95:1063-76

39. Murariu M, Bonnaud L, Yoann P, Fontaine G, Bourbigot S, Dubois P. New trends in polylactide (PLA)-based materials: "green" PLA-calcium sulfate (nano)composites tailored with flame retardant properties. Polym Degrad Stabil. 2010;95:37481. 
40. Chow WS, Teoh EL. Flexible and flame resistant poly(lactic acid)/organomontmorillonite nanocomposites. J Appl Polym Sci. 2015;132:41253.

41. Ye L, Ren J, Cai SY, Wang ZG, Li JB. Poly(lactic acid) nanocomposites with improved flame retardancy and impact strength by combining of phosphinates and organoclay. Chin J Polym Sci. 2016;34:785-96.

42. Kashiwagi T, Harris RH, Zhang X, Briber RM, Cipriano BH, Raghavan SR, et al. Flame retardant mechanism of polyamide 6-clay nanocomposites. Polymer. 2004;45:881-91.

43. Qin H, Zhang S, Zhao C, Hu G, Yang M. Flame retardant mechanism of polymer/clay nanocomposites based on polypropylene. Polymer. 2005;46:8386-95.

44. Louati S, Baklouti S, Samet B. Geopolymers based on phosphoric acid and illito-kaolinitic clay. Adv Mater Sci Eng. 2016;2016:2359759.

45. Stoclet G, Sclavons M, Lecouvet B, Devaux J, Velthem PV, Boborodea A, et al. Elaboration of poly(lactic acid)/halloysite nanocomposites by means of water assisted extrusion: structure, mechanical properties and fire performance. RSC Advances. 2014;4:57553-63.

46. Kontou E, Niaounakis M, Georgiopoulos P. Comparative study of PLA nanocomposites reinforced with clay and silica nanofillers and their mixtures. J Appl Polym Sci. 2011;122:1519-29.

47. Guo Y, Yang K, Zuo X, Xue W, Marmorat C, Liu Y, et al. Effects of clay platelets and natural nanotubes on mechanical properties and gas permeability of poly(lactic acid) nanocomposites. Polymer. 2016;83:246-59.

48. Kaleemulla KM, Siddeswarappa B. Influence of fiber orientation on the in-plane mechanical properties of laminated hybrid polymer composites. J Reinf Plast Compos. 2010;29:1900-14.

49. Pluta M, Galeski A, Alexandre M, Paul MA, Dubois P. Polylactide/ montmorillonite nanocomposites and microcomposites prepared by melt blending: structure and some physical properties. J Appl Polym Sci. 2002;86:1497-506.

50. Chapple S, Anandjiwala R, Ray S. Mechanical, thermal, and fire properties of polylactide/starch blend/clay composites. J Therm Anal Calorim. 2012;113:703-12. 